\title{
Contentment in general practice - for now
}

Sources of poor morale and high levels of stress among GPs include our personalities, patients, and the system itself. Prior to the GP Charter in 1966, Cartwright found high levels of stress, discontent, and frustration among UK GPs, which had changed little on follow-up in 1977. 1,2 High levels of stress are associated with increased workload which, in turn, leads to poor mental health and burnout in the profession. Maslach et $a^{3}$ described how in burnout, 'what started out as important, meaningful, and challenging work becomes unpleasant, unfulfilling, and meaningless. Energy turns into exhaustion, involvement turns into cynicism, and efficacy turns into ineffectiveness'. Burnout is often associated with anxiety and depression but is distinct from both in that burnout presents with work-related rather than physical or biological symptoms. Thankfully, more GPs seem to fear burnout than suffer from it.

In an attempt to understand the causal links between stress and burnout McManus et al, in a 3-year longitudinal study of 331 hospital and GPs in the UK surveyed in 1997 and 2000, showed a dynamic pattern to stress and burnout. ${ }^{4}$ In a vicious circle, emotional exhaustion makes doctors more stressed and stress makes doctors more emotionally exhausted. Interestingly, the cynicism of burnout may be protective against excessive stress, acting as an adaptation and ego defence mechanism. Doctors are high achievers and the risk of burnout is ever present as the drive for achievement increases stress both directly and by increasing emotional exhaustion.

GPs often look after distressed people for whom medicine can do little. Patients who are unable to marshal the motivation to extract themselves from undesirable situations may be the very stuff of general practice to some doctors but deeply frustrating to others. To be effective most doctors have to learn to ration their compassion and to become more emotionally detached for their own sakes. ${ }^{5}$
There are many similarities between doctors who are burnt-out and poorly performing doctors, who are increasingly likely to face sanction from regulatory and legal authorities when constructive criticism from colleagues might be more beneficial.

Not surprisingly, doctors would like the system they work in to take their views, and indeed welfare, more seriously. Paymasters throughout the world are now focused on cost containment and have introduced clinical competitors who can do selected clinical tasks and procedures just as well as doctors, and more cheaply.

In a 1997 study comparing stress and morale in general practice in two healthcare systems in the island of Ireland, GPs in Northern Ireland, where the NHS serves the population, reported significantly more stress and poor morale than in the Republic of Ireland. Seventy per cent of patients in the Irish Republic pay the GP directly and a large number of GPs also hold contracts to provide meanstested general medical services (GMS) free at the point of use to the remaining $30 \%$ of the population. Having a GMS contract has been associated with significantly high levels of stress. ${ }^{6}$ The more tightly-managed NHS system gave Northern Irish GPs less control over their workload compared with their southern counterparts, which was bad for morale. The longitudinal Whitehall study of British civil servants showed that those with high job control had only half the risk of developing new coronary heart disease when compared to those, usually lower-ranking colleagues, with low job control. ${ }^{7}$ In a recent study from Quebec, patients who had experienced a first myocardial infarction with chronic job strain, where they had high demand but low decision latitude, were at double the risk of a next coronary event. ${ }^{8}$

Prior to the 2004 GMS contract in the UK, GPs' job satisfaction in England had fallen to its lowest point in over a decade. ${ }^{9}$ As reported in this issue of the Journal, GPs' perceptions 3 years after the introduction of the new contract have changed a lot, with an overall increase in job satisfaction following an increase in remuneration and being able to opt out of out-of-hours coverage. ${ }^{10}$ Responders noted that the 2004 contract decreased professional autonomy and increased administrative and clinical workloads. However, doctors conceded that the new contract had made a positive impact on the quality of care provided to patients with its focus on chronic illness.

Denmark has strongly regulated primary care that is financed through central taxation, and its GPs are paid partly through capitation and partly through fees for their services. In a study from the County of Aarhus, again reported in this issue of the Journal, ${ }^{11}$ nearly $27 \%$ of GPs are suffering from varying stages of burnout. While this is a significant occupational health problem for the doctors, an unhealthy medical workforce is a hazard for patients, and needs urgent attention.

The UK 2004 contract has reduced the working week by almost 4 hours while increasing annual income by nearly $£ 20000$. It would be difficult to not be pleased with such an outcome. British general practice is an attractive well-paid career and long may it continue. Most doctors in the study by Whalley et $a l^{10}$ in this issue think that they have traded autonomy for better pay, fewer working hours, and improved public health outcomes in the area of chronic disease. Decreased autonomy inevitably leads to less control over workload, the content of work, and eventually over the direction of general practice. However, a small ethnographic study of two practices in England found little evidence that the new 2004 contract threatened the internal motivation or core values of the doctors. ${ }^{12}$

For modern primary care, the ideal of cradle-to-grave 24-hour care is too much to bear and was probably crushed under the weight of patient and government expectations that GPs should be available 
on demand. It may not matter that GPs have traded a bit of autonomy for the greater good when clinical freedom is now so difficult to defend; or that general practice mainly provides Monday to Friday daytime care in the NHS and many other healthcare systems.

The research on the dangers of stress and poor morale has convinced doctors, and more importantly their negotiators, that quality of life needs to be taken more seriously. What happens in the NHS is important internationally as even marketdriven healthcare systems look to it for trends and ideas. As there seems to be much in the 2004 contract for GPs it will become a reference point for doctors in other international healthcare systems.

Most governments seem to dread negotiations on pay and rations with doctors, as every new contract seems to come in over the dead bodies of the profession, who often discover well-hidden merits in the existing contract that a previous generation opposed. The merits in the 2004 contract for doctors and populations are not at all hidden, but a government may easily put aside its dread of doctors and decide to rebalance the benefits specifically in favour of the patient.

In the Culture of Contentment, ${ }^{13}$ Galbraith wrote about how the selfinterested perspective of the well off could shape modern political and economic culture in the short term. A number of troubling questions emerge from a newfound contentment. Do the contented innovate, question, and advocate for patients or themselves? Is it possible to have some fellow feeling for the trials and tribulations of patients from a base of contentment? Will a contented profession with diminished autonomy be easily driven off course by externally set targets and politicians hell bent on improving the health of the nation for electoral advantage? For sure GPs in Denmark would like a bit more contentment - for now.

\section{Thomas O'Dowd}

Professor of General Practice,

Trinity College, Dublin.

\section{REFERENCES}

1. Cartwright A. Patients and their doctors: a study of general practice. London: Routledge \& Kegan Paul, 1967.

2. Cartwright A, Anderson R. General practice revisited. A second study of patients and their doctors. London: Tavistock, 1981.

3. Maslach C, Schaufeli WB, Leiter MP. Job burnout. Annu Rev Psychol 2001; 52: 397-422.

4. McManus IC, Winder BC, Gordon D. The causal links between stress and burnout in a longitudinal study of UK doctors [research letter]. Lancet 2002; 359: 2089-2090.

5. O'Dowd TC. To burn out or to rust out in general practice [editorial]. J R Coll Gen Pract 1987; 37(300): 290-291.

6. Gilliland AEW, Sinclair H, Cupples ME, et al. Stress and morale in general practice: a comparison of two health care systems. Br J Gen Pract 1998; 48 1663-1667.

7. Bosma H, Marmot MG, Hemingway $\mathrm{H}$, et al. Low job control and risk of coronary heart disease in Whitehall II (prospective cohort) study. BMJ 1997; 314(7080): 558-565.

8. Aboa-Eboulé C, Brisson C, Maunsell E, et al. Job strain and risk of acute recurrent coronary heart disease events. JAMA 2007; 298(14): 1652-1660.

9. Sibbald B, Bojke C, Gravelle H. National survey of job satisfaction and retirement intentions among general practitioners in England. BMJ 2003; 326: 22.

10. Whalley D, Gravelle, Sibbald B. Effect of the new contract on GPs' working lives and perceptions of quality of care: a longitudinal survey. Br J Gen Pract 2008; 58(546): 8-14.

11. Brøndt A, Sokolowski I, Olesen F, Vedsted P. Continuing medical education and burnout among Danish GPs. Br J Gen Pract 2008; 58(546): 15-19.

12. McDonald R, Harrison S, Checkland K, et al. Impact of financial incentives on clinical autonomy and internal motivation in primary care: ethnographic study. BMJ 2007; 334: 1357-1359.

13. Galbraith JK. The culture of contentment. Boston: Houghton Mufflin Company, 1992.

DOI: 10.3399/bjgp08X263730

\section{ADDRESS FOR CORRESPONDENCE}

\section{Thomas O'Dowd}

Department of Public Health and Primary Care, Trinity College Centre for Health

Sciences, Adelaide and Meath Hospitals, Tallaght, Dublin 24, Ireland.

E-mail: todowd@tcd.ie

\section{Work patterns in UK general practice: turning the clock back?}

The 1966 contract for UK GPs can be judged to have brought about a remarkable renaissance in primary care. For those unfamiliar with the history, it is worth recalling what it was like before then. Most practices were single-handed, and there was no incentive to invest in staff or premises. GPs were memorably faced with the choice of maximising their income by looking after large lists of patients, or having smaller lists, employing staff, and investing in their premises and surviving on lower incomes. Significantly, the 1966 contract marked the end of the 'assistant with a view'. These were doctors unable to get a practice of their own, and employed by existing doctors 'with a view' to taking over the practice in due course. Such doctors ended up trapped, waiting for a partnership that came late or not at all, and working for another doctor at a lower rate of pay. The 1966 contract introduced a fee structure with a number of different elements, specifically rewarding doctors working in partnerships, providing generous arrangements for investing in premises, and reimbursement for employing staff.

Over time, much of this complex structure has been eroded, first with the 1990 contract, followed by personal medical services (PMS) contracts. The 2004 changes found in the new general medical services (GMS) contract significantly replaced contracts between the PCT and individual principals, with contracts with practices. Despite that, many of the changes since 1966 are here to stay. The performance management 